\title{
Rice Husk Supported Catalysts for Degradation of Chlorobenzenes in Capillary Microreactor
}

\author{
Abdulelah Thabet, Chanbasha Basheer, Than Htun Maung, \\ Hasan Ali Al-Muallem, and Abdul Nasar Kalanthoden \\ Department of Chemistry, King Fahd University of Petroleum and Minerals, Dhahran 31261, Saudi Arabia \\ Correspondence should be addressed to Chanbasha Basheer; cbasheer@kfupm.edu.sa
}

Received 16 January 2015; Revised 21 May 2015; Accepted 4 June 2015

Academic Editor: Maofeng Zhang

Copyright (C) 2015 Abdulelah Thabet et al. This is an open access article distributed under the Creative Commons Attribution License, which permits unrestricted use, distribution, and reproduction in any medium, provided the original work is properly cited.

\begin{abstract}
Chlorinated organic pollutants are persistent, toxic, and ubiquitously distributed environmental contaminants. These compounds are highly bioaccumulative and adversely affect the ozone layer in the atmosphere. As such, their widespread usage is a major cause of environmental and health concern. Therefore, it is important to detoxify such compounds by environment friendly methods. In this work, rice husk supported platinum (RHA-Pt) and titanium (RHA-Ti) catalysts were used, for the first time, to investigate the detoxification of chlorobenzenes in a glass capillary microreactor. High potential (in $\mathrm{kV}$ range) was applied to a reaction mixture containing buffer solution in the presence of catalyst. Due to high potential, hydroxyl and hydrogen radicals were produced, and the reaction was monitored by gas chromatography-mass spectrometry. The main advantage of this capillary reactor is the in situ generation of hydrogen for the detoxification of chlorobenzene. Various experimental conditions influencing detoxification were optimized. Reaction performance of capillary microreactor was compared with conventional catalysis. Only 20 min is sufficient to completely detoxify chlorobenzene in capillary microreactor compared to $24 \mathrm{~h}$ reaction time in conventional catalytic method. The capillary microreactor is simple, easy to use, and suitable for the detoxification of a wide range of chlorinated organic pollutants.
\end{abstract}

\section{Introduction}

Chlorinated organic compounds (COCs) are a large class of synthetic and natural organic molecules that contain one or more chlorine atoms. They are one of the most versatile and widely used classes of compounds in the industrial world [1]. For example, COCs are used as anesthetics, pesticides and herbicides, fungicides, dyes, pharmaceuticals, plant growth regulators, heat-transfer medium, and industrial solvents and are byproducts of several industries (e.g., oil refining, paper industry, plastics or adhesives manufacturing, etc.) [1-6]. The importance of these chlorinated chemicals lies in the fact that chlorine bonds strongly to other elements, and this makes chlorine an important ingredient and precursor in building new compounds. Unfortunately, this property is also one of the reasons why chlorinated compounds, once formed, are hazardous. Due to this strong bonding, it is hard to break down COCs and hence they persist in nature. Chlorinecontaining compounds also adversely affect the ozone layer in the atmosphere. As such, their widespread usage is a major cause of environmental and health concern. Moreover, COCs are among the most widely distributed pollutants in wastewaters and contaminated ground waters [7]. They are listed as priority pollutant by the U.S. Environmental Protection Agency (USEPA) [8]. Due to their lipophilic nature (i.e., easy to concentrate in fats of animals, which leads to biomagnification), polychlorinated aromatic compounds which are environmentally stable and persistent in nature tend to bioaccumulate in the food chain [9]. Bioaccumulation indirectly affects human as residues of these compound are detected in food and human adipose tissues, milk, and serum fat [10]. COCs can cause serious environmental problems because they are difficult to be decomposed biologically. Exposure to them can lead to kidney, liver, blood, and central nervous system damages. Therefore, there is an urgent need to develop efficient and cost-effective methods to detoxify and destroy them [11]. Several remediation methods have been developed to eliminate COCs, such as oxidation methods and incineration $[12,13]$; mechanochemical methods and reductive 


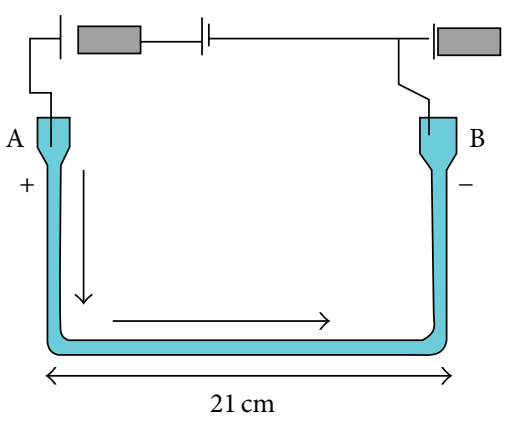

(a)

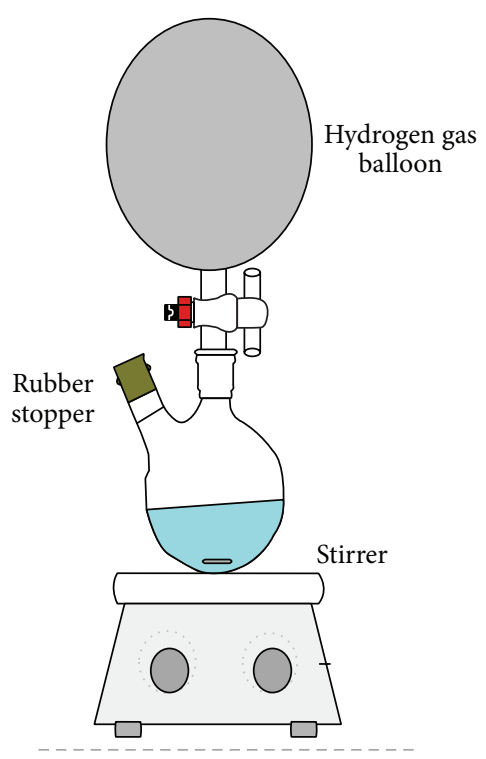

(b)

FIGURE 1: Schematics of (a) the glass capillary microreactor for transfer hydrogenolysis reaction. (b) Conventional experimental set up for hydrodechlorination reaction with external supplied hydrogen gas source.

methods such as electrochemical [14], photochemical [15], ultrasonic [16], microbial [17], and radiolytic and thermal [18] reductive methods have been developed. Besides reductive methods, bioremediation using natural biological activity by means of aerobic and anaerobic biodegradation of chlorinated compounds has also been extensively studied [19-21]. Catalytic hydrodechlorination (HDC), which involves the reductive cleavage of a $\mathrm{C}-\mathrm{Cl}$ bond by highly reactive atomic hydrogen $(\mathrm{H})$, is a green (environmentally friendly) and costeffective technique. So far, the effective degradation of various COCs, including CBs and CPs (chlorophenols), has been successfully achieved [11]. HDC is one of the most promising alternative methods for the detoxification of COCs; it operates in liquid or gas phase using different catalytic systems yielding none or partially chlorinated hydrocarbons and $\mathrm{HCl}$ as products. Basically, $\mathrm{HDC}$ is the reaction of COCs $(\mathrm{R}-\mathrm{Cl})$ with hydrogen to form a carbon-hydrogen bond and $\mathrm{HCl}$. It can be represented by the following chemical equation:

$$
\mathrm{R}-\mathrm{Cl}+\mathrm{H}-\mathrm{H} \longrightarrow \mathrm{R}-\mathrm{H}+\mathrm{H}-\mathrm{Cl}
$$

Moreover, this reaction can be done in mild ambient conditions and it forms no harmful side-products and could eventually be selective towards chloride removal $[22,23]$. HDC is a simple, efficient and clean method. The hydrogen source in the HDC reaction can be molecular hydrogen $\left(\mathrm{H}_{2}\right)$ or any other hydrogen donors such as formic acid and its salts or alcohols such as isopropanol and hydrazine $[7,24,25]$. This reaction is quite exothermic and thus requires the presence of a catalyst to drive it to completion. The reaction also requires selective cleavage of $\mathrm{C}-\mathrm{Cl}$ bond and therefore requires selective catalysts. Several hydrodechlorination metallic catalysts and support have been reported in the literature [26, 27]. For example, palladium, ruthenium, rhodium, iridium, rhenium, titanium, platinum, and Raney nickel [2, 28-30] were used as catalysts. Where alumina, activated carbon [2], $\mathrm{Ni}-\mathrm{Mo} /$ C [5], and silica are among the catalyst supports for the most commonly used ones in the HDC reactions, the catalytic activity of HDC does not only depend on the size of the metals but also on the nature of the support and the preparation method of the support [31].

Rice husk (RH) is an agricultural waste and the ash contains about $92-95 \%$ silica $\left(\mathrm{SiO}_{2}\right)$. It is highly porous with lightweight and high surface area. Many publications reported the use of rice husk ash as catalyst support for metals [32]. HDC processes can be performed in batch reactors for small and medium-scale processes and/or continuousflow reactors for large-scale processes. A glass capillary-based microreactor (as shown in Figure 1(a)) was fabricated for this study and the glass is chemically inert, optically clear, and nonporous, hence making it a suitable material $[33,34]$. The present study investigates detoxification of chlorinated aromatic compounds over silica-platinum and silica-titanium supported catalysts under mild condition by using buffered solutions in a capillary microreactor.

\section{Experimental}

2.1. Materials. Platinum chloride $\left(\mathrm{PtCl}_{2}\right)$ used as the source of platinum and titanium dioxide $\left(\mathrm{TiO}_{2}\right)$ as the source of titanium were purchased from Merck, Darmstadt, Germany. Other materials used are nitric acid (65\% purity), sodium hydroxide pellets (99\%), and acetone (99.5\%) (Sigma-Aldrich, St Louis). Cetyltrimethylammonium bromide (CTAB, 98\%) and methylene blue were purchased from Sigma Aldrich. Rice husk $(\mathrm{RH})$ was obtained from a rice milling company in Penang. A $100 \mathrm{ppm}$ standards of 1,2-dichlorobenzene (1,2DCB), 3-dichlorobenzene (1,3-DCB), 1,4-dichlorobenzene 
(1,4-DCB), 1,2,4-trichlorobenzene (1,2,4-TCB), hexachlorobenzene (HCB) and benzene (Sigma-Aldrich, $\geq 99.0 \%$ ) were prepared.

2.2. Preparation of the Catalysts. $30 \mathrm{~g}$ of clean rice husk was stirred with $750 \mathrm{~mL}$ of $1.0 \mathrm{M} \mathrm{HNO}_{3}$ at room temperature for $24 \mathrm{~h}$. The cleaned RH was washed with copious amount of distilled water to constant $\mathrm{pH}$, then dried in an oven at $100^{\circ} \mathrm{C}$ for $24 \mathrm{~h}$, and burned in a muffle furnace at $600^{\circ} \mathrm{C}$ for $6 \mathrm{~h}$ so as to obtain white rice husk ash (RHA) [32]. About $3.0 \mathrm{~g}$ of RHA was added to $350 \mathrm{~mL}$ of $1.0 \mathrm{~mol} \mathrm{~L}^{-1} \mathrm{NaOH}$ in a plastic container and stirred for $24 \mathrm{~h}$ at room temperature to get sodium silicate solution. About $3.6 \mathrm{~g}$ of CTAB (1:1.2, $\mathrm{Si}$ : CTAB molar ratio) was added into the sodium silicate solution and stirred to dissolve completely. This solution was titrated with $3.0 \mathrm{~mol} \mathrm{~L}^{-1} \mathrm{HNO}_{3}$ at a rate of ca. $1.0 \mathrm{~mL} \mathrm{~min}^{-1}$ with constant stirring until $\mathrm{pH}$ 3.0. The resulting gel was aged for 5 days, then filtered and washed thoroughly with distilled water, and finally washed with acetone. The gel was dried at $110^{\circ} \mathrm{C}$ for $24 \mathrm{~h}$, ground to fine powder, and calcined at $500^{\circ} \mathrm{C}$ in a muffle furnace for $5 \mathrm{~h}$ and then labeled as RHA-silica powder. Same procedure was followed for the preparation of RHA-silica solution of $10 \mathrm{wt} . \% \mathrm{Pt}$ of $\mathrm{PtCl}_{2}$ which was dissolved in $50 \mathrm{~mL}$ of $3 \mathrm{~mol} \mathrm{~L}^{-1} \mathrm{HNO}_{3}$ and titrated. Similarly, solution of $10.0 \mathrm{wt} . \% \mathrm{Ti}$ of $\mathrm{TiO}_{2}$ was dissolved in $50 \mathrm{~mL}$ of $3 \mathrm{~mol} \mathrm{~L}^{-1} \mathrm{HNO}_{3}$ and titrated. The resulting gels were treated as described above. The resulting powders were labeled as RHA-Pt and RHA-Ti, respectively.

2.3. Catalysts Characterization. The prepared RHA-Pt and RHA-Ti samples were characterized using Fourier transform infrared (FTIR) spectroscopy, $\mathrm{N}_{2}$ adsorption-desorption analysis, Field-Emission Scanning Electron Microscope (FESEM), and energy dispersive spectrometry (EDX).

2.4. HDC Reaction in a Capillary Microreactor. The capillary microreactor was used for studying the detoxification of chlorinated organic compounds. Several glass capillary microreactores $(7 \mathrm{~cm}, 14 \mathrm{~cm}$, and $21 \mathrm{~cm})$ were designed for the HDC reaction as shown in Figure 1(a). The capillary microreactor and reservoirs A and B were filled with $2.5 \mathrm{mmol}$ of buffer solution of different $\mathrm{pH}(2,7$ and 10$)$ and $12.5 \mathrm{mg}$ of catalyst and $100 \mu \mathrm{L}$ of the mixture standard (8270 MagaMix) were introduced into the capillary microreactor at the reservoir A. Platinum wires were used as the electrodes and high voltage $(1-5 \mathrm{kV})$ was applied. No air bubbles were found inside the capillary tube during the reaction. A reaction potential (1$5 \mathrm{kV}$ ) and $200 \mu \mathrm{A}$ current were applied to reservoir A, while reservoir B was connected to ground. HDC reaction was carried out at room temperature and ambient pressure, all experiments were repeated three times, to get more accurate results, and the reaction time was controlled manually. The basic arrangement of the capillary microreactor, in which the experimental studies for the detoxification of chlorinated organic compounds were carried out, is depicted in Figure 1(a). The setup of the capillary microreactor system is composed of a high voltage power supply, glass capillary microreactor, and platinum wires.

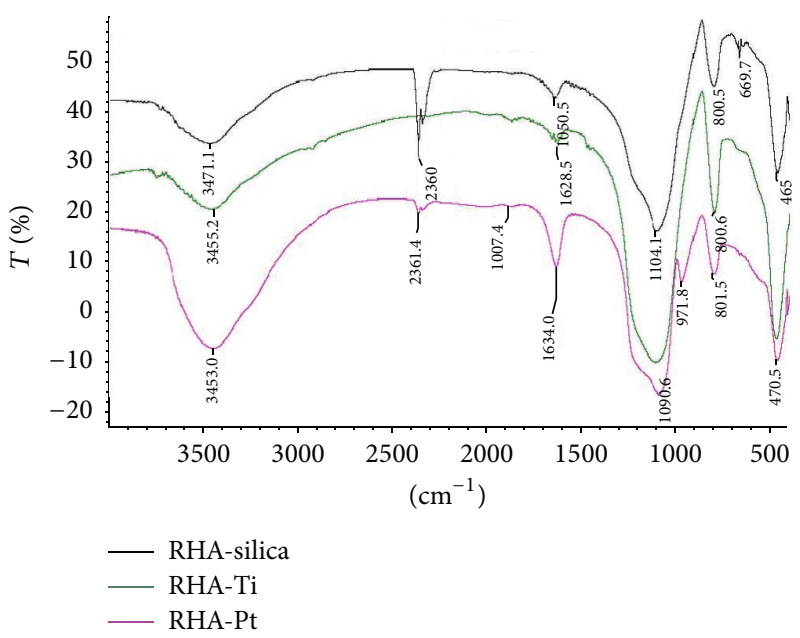

FIGURE 2: The FT-IR spectra of RHA-silica and metal modified silica by loading (Ti and Pt) (a) $\mathrm{RHA}-\mathrm{SiO}_{2}$, (b) RHA-Ti, and (c) RHA-Pt.

2.5. Catalytic Hydrodechlorination (HDC) by Conventional Method. HDC reactions of 8270 MagaMix with molecular hydrogen gas were carried out at room temperature and ambient pressure by using buffered solutions in a round bottom flask. Hydrogen was introduced by balloon (Figure 1(b)). In a typical HDC procedure, $10 \mathrm{~mL}$ of buffer solution was spiked with $100 \mathrm{ppm}$ chlorobenzenes, and $50 \mathrm{mg}$ of supported $\mathrm{Pt}$ catalyst RHA-Pt, or $50 \mathrm{mg}$ of RHA-Ti was added [2]. The mixture was magnetically stirred at $100 \mathrm{rpm}$ with a stirring bar and after the desired time $(2 \mathrm{~h}, 16 \mathrm{~h}, 24 \mathrm{~h})$, the samples reaction mixtures were collected, and separated by $1.5 \mathrm{~mL}$ heptane for $5 \mathrm{~min}$. The identification and quantification of all CBs was performed by GC-MS, and catalytic conversion was calculated by analyzing the peak areas of the target compounds. The setup is displayed in Figure 1(b). The buffer solutions used in the HDC reactions were prepared as follows: (a) phosphate buffer: phosphoric acid $\mathrm{H}_{3} \mathrm{PO}_{4}\left(2 \mathrm{~mol} \mathrm{~L}^{-1}\right)$ was added to a solution of $\mathrm{K}_{2} \mathrm{HPO}_{4}\left(2 \mathrm{~mol} \mathrm{~L}^{-1}\right)$ until the $\mathrm{pH}$ reaches 2; (b) phosphate buffer: a solution of $\mathrm{NaH}_{2} \mathrm{PO}_{4}$ $\left(0.021 \mathrm{~mol} \mathrm{~L}^{-1}\right)$ was added to a solution of $\mathrm{Na}_{2} \mathrm{HPO}_{4}$ $\left(0.029 \mathrm{~mol} \mathrm{~L}^{-1}\right)$ until the $\mathrm{pH}$ reaches 7 ; (c) borate buffer: a solution of sodium tetraborate $\left(0.013 \mathrm{~mol} \mathrm{~L}^{-1}\right)$ was added to a solution of $\mathrm{NaOH}\left(0.018 \mathrm{~mol} \mathrm{~L}^{-1}\right)$ until the $\mathrm{pH}$ reaches 10 .

\section{Result and Discussion}

3.1. Catalysts Characterization. The FT-IR analysis was carried out in Nicolet 6700 FT-IR using the $\mathrm{KBr}$ pellet method. Figure 2 shows the FT-IR spectra of the catalysts RHA-Ti and RHA-Pt and RHA-SiO ${ }_{2}$ obtained in the wavenumber range $400-4000 \mathrm{~cm}^{-1}$. The broad band in the range $3471-$ $3455 \mathrm{~cm}^{-1}$ is due to the stretching vibration of $\mathrm{O}-\mathrm{H}$ bonds in $\mathrm{Si}-\mathrm{OH}$ and the $\mathrm{HO}-\mathrm{H}$ of water molecules adsorbed on the materials surface. The band at $1628-1650 \mathrm{~cm}^{-1}$ is due to the bending vibration of $\mathrm{H}_{2} \mathrm{O}$ trapped in the silica matrix. The band around $1104 \mathrm{~cm}^{-1}$ was shifted to a lower wavenumber for metal incorporated RHA. The band at $1090-1104 \mathrm{~cm}^{-1}$ is attributed to asymmetric $\mathrm{Si}-\mathrm{O}-\mathrm{Si}$ stretching vibration, from 


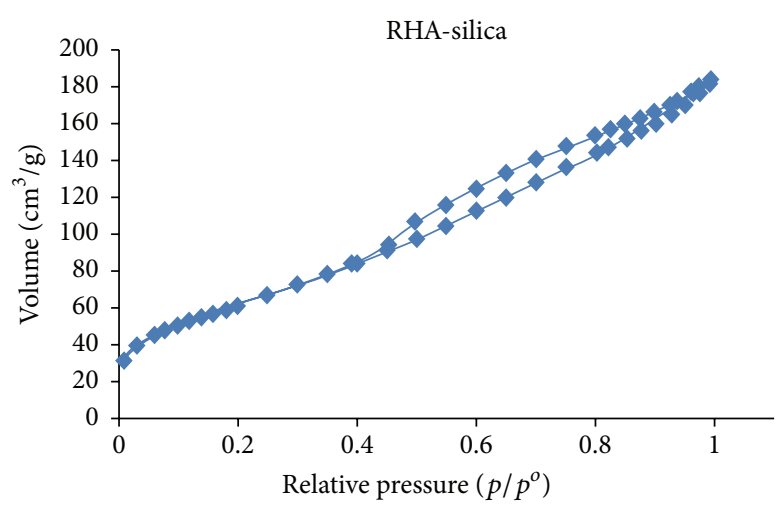

(a)

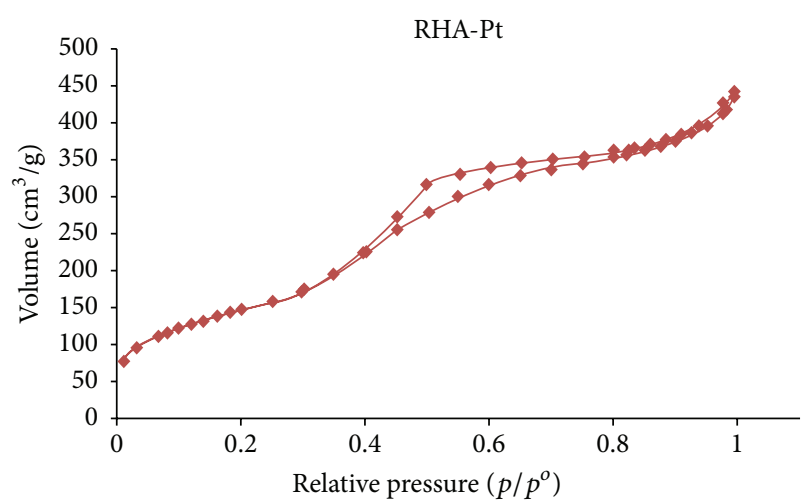

(b)

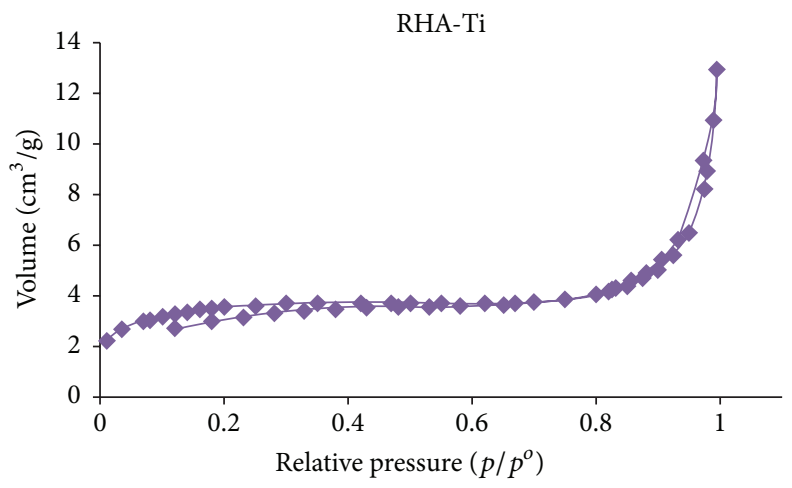

(c)

Figure 3: The nitrogen adsorption-desorption analysis of materials (a) RHA-silica, (b) RHA-Pt, and (c) RHA-Ti.

the structural siloxane bond. The band at $971.8 \mathrm{~cm}^{-1}$ can be attributed to the symmetric stretching vibration of $\mathrm{Si}-\mathrm{OH}$ [32]. The intensity of this peak decreased in RHA-Ti and appears as a shoulder. This might indicate that some metal ions are attached on the surface of the silica as $\mathrm{Si}-\mathrm{O}-\mathrm{M}$ from the original $\mathrm{Si}-\mathrm{O}-\mathrm{H}$ or $\mathrm{Si}-\mathrm{O}-\mathrm{Si}$ silica structure. The absorption bands at about $465 \mathrm{~cm}^{-1}$ and $470.5 \mathrm{~cm}^{-1}$ are due to $\mathrm{Si}-\mathrm{O}-\mathrm{Si}$ bending vibrations [32]. The bands at $800-802 \mathrm{~cm}^{-1}$ are due to the deformation and bending modes of $\mathrm{Si}-\mathrm{O}-\mathrm{Si}$.

The specific surface area, pore volume, and pore size distribution of the prepared catalysts were determined using $\mathrm{N}_{2}$ adsorption-desorption on a Micromeritics ASAP 2020 volumetric instrument. Nitrogen sorption isotherms were performed at liquid nitrogen temperature $\left(-195.786^{\circ} \mathrm{C}\right)$. The $\mathrm{N}_{2}$ adsorption-desorption isotherm of RHA-silica, RHA-Pt, and RHA-Ti is shown in Figure 3. The surface area, pore diameter, and pore volume were calculated using BarrettJoyner-Halenda model and the results are displayed in Table 1. The average mesopore size was, for all catalysts, around 4 to $4.85 \mathrm{~nm}$. We see that RHA-silica has high surface area of $225.4306 \mathrm{~m}^{2} / \mathrm{g}$ while RHA-Ti catalyst has associated BET surface area and pore volume of $12.6548 \mathrm{~m}^{2} / \mathrm{g}$ and $0.012738 \mathrm{~cm}^{3} / \mathrm{g}$, respectively. The incorporation of $\mathrm{Ti}$ into silica reduced its surface area and pore volume compared to RHA-silica due to the pore blocking by the agglomerated particles [35]. However, in the RHA-Pt supported catalyst,
TABLE 1: The nitrogen adsorption-desorption analysis parameters of materials.

\begin{tabular}{lccc}
\hline Catalyst & $\begin{array}{c}\text { BET surface } \\
\text { area }\left(\mathrm{m}^{2} / \mathrm{g}\right)\end{array}$ & $\begin{array}{c}\text { Pore volume } \\
\left(\mathrm{cm}^{3} / \mathrm{g}\right)\end{array}$ & $\begin{array}{c}\text { Average pore } \\
\text { size }(\mathrm{nm})\end{array}$ \\
\hline RHA-silica & 225.4306 & 0.273179 & 4.84725 \\
RHA-Pt & 538.0725 & 0.637532 & 4.73938 \\
RHA-Ti & 12.6548 & 0.012738 & 4.02638 \\
\hline
\end{tabular}

the incorporation of $\mathrm{Pt}$ into silica matrix increased its surface area $\left(538.0725 \mathrm{~m}^{2} / \mathrm{g}\right)$ and pore volume $\left(0.637532 \mathrm{~cm}^{3} / \mathrm{g}\right)$ compared to those of the support RHA-silica. This could be good dispersion of Pt particles within the silica matrix [32].

Field-Emission Scanning Electron Microscope (FESEM) (Tescan Lyra-3) was used to investigate the surface morphology and the general morphological features of the prepared RHA-silica and RHA-Pt nanoparticles. The EDX measurements were also used to confirm the percentage and the atomic ratio of the components in the prepared catalyst. Figure 4 shows the FESEM and EDX images of (a) RHAsilica sample, (b) RHA-Pt, and (c) RHA-Ti. The RHA-silica particles have flakes structure whereas the RHA-Pt particles have spherical structure with porous surfaces. While the RHA-Ti particles have rod-like morphology and less porous surfaces compared to RHA-silica. 

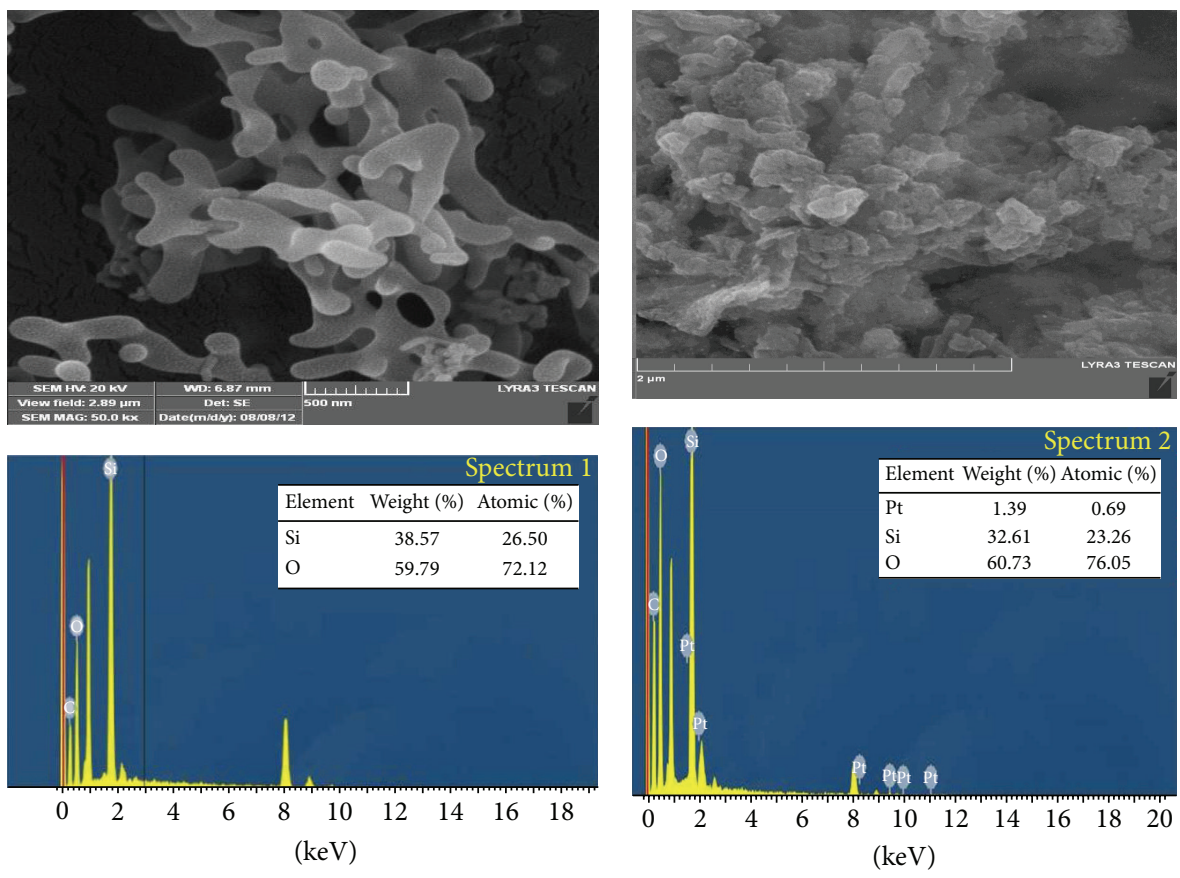

Full scale 1571 cts cursor: 2.952 (35 cts)

Full scale 1368 cts cursor: -0.054 (7 cts)

(a)

(b)
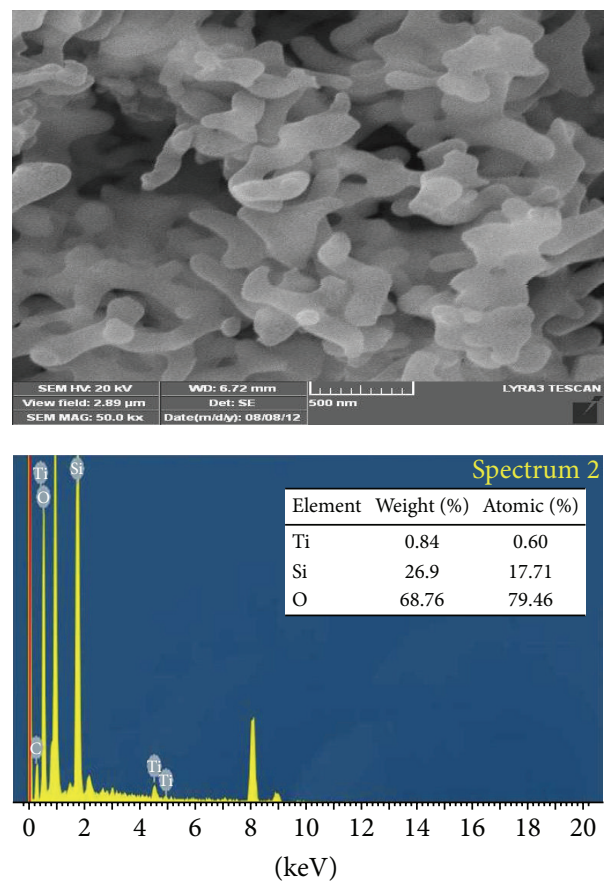

Full scale 1368 cts cursor: -0.054 ( 4 cts)

(c)

FIgURE 4: The FESEM and EDX images of (a) RHA- silica, (b) RHA-Pt, and (c) RHA-Ti.

3.2. Detoxification of COCs Using Capillary Microreactor. To optimize the HDC reactions in the capillary microreactor, analytical factors like applied potential, reaction time, length of the capillary, and $\mathrm{pH}$ of buffer solution were investigated to determine the most favorable reaction conditions. Temperature was kept constant at room temperature throughout the reactions. The results were then compared with those of the conventional method. The identification and quantitative results were determined from GC-MS data.

3.2.1. Effect of Reaction Time. Reaction time is one of the most important factors in the HDC reactions. Therefore, various 


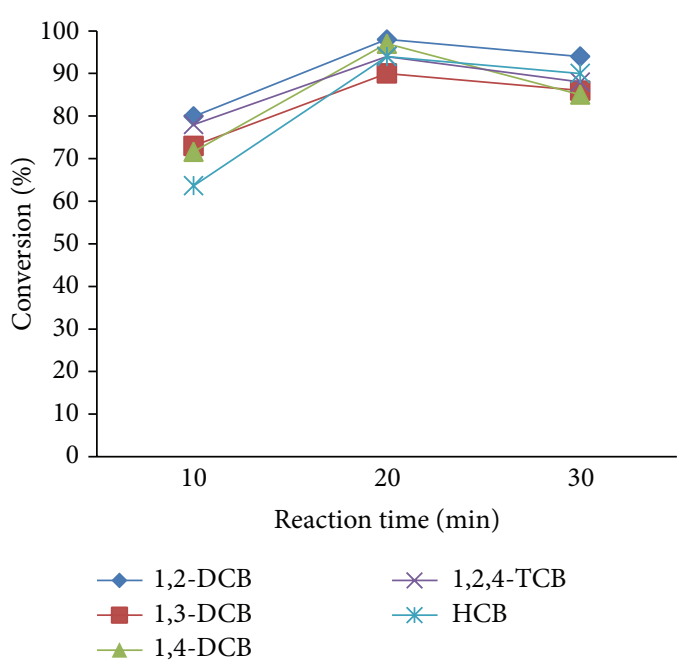

(a)

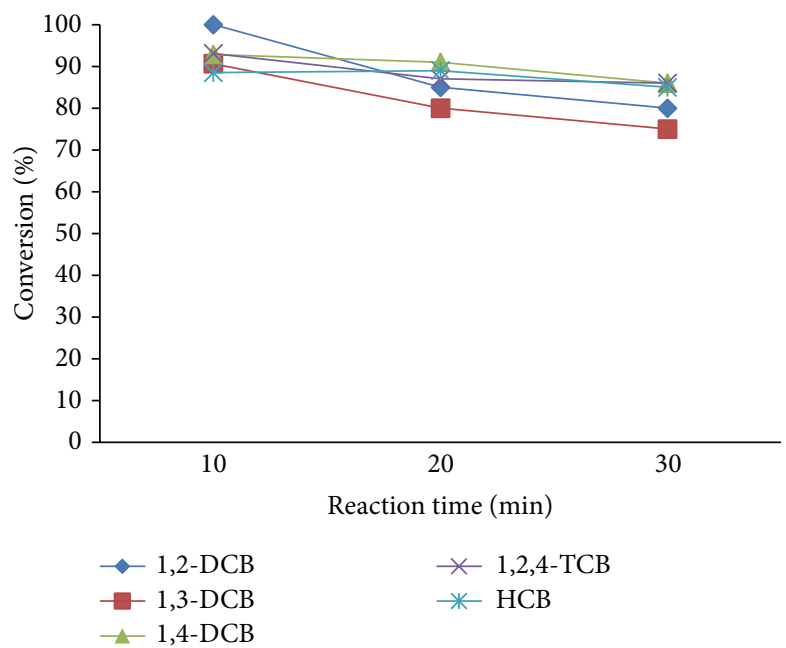

(b)

FIGURE 5: Effect of different reaction times on the conversion ratio of chlorobenzenes (CBs) in the capillary microreactor of $21 \mathrm{~cm}$ length, applied potential $3 \mathrm{kV}$ (a) using $\mathrm{pH} 7$ and RHA-Pt catalyst and (b) using $\mathrm{pH} 10$ and RHA-Ti catalyst.

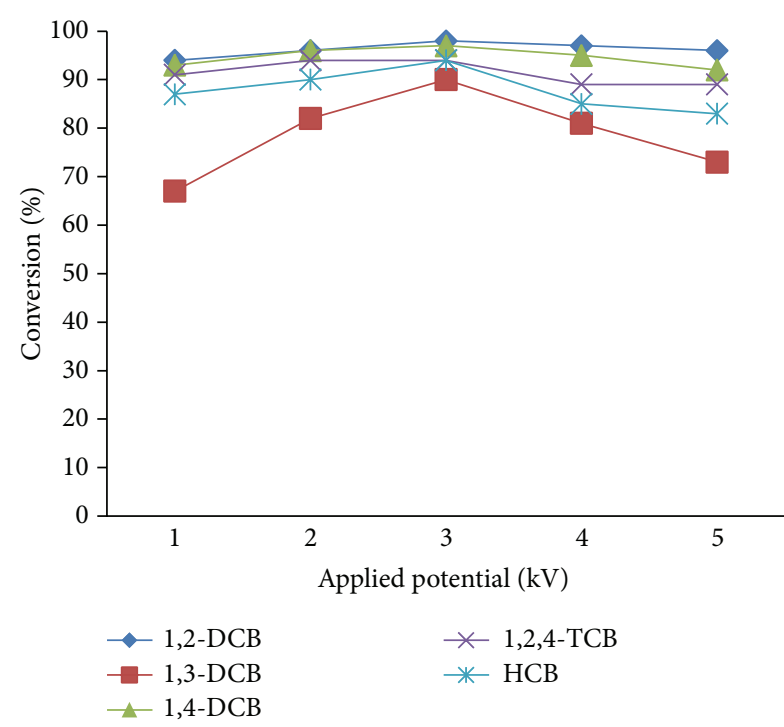

(a)

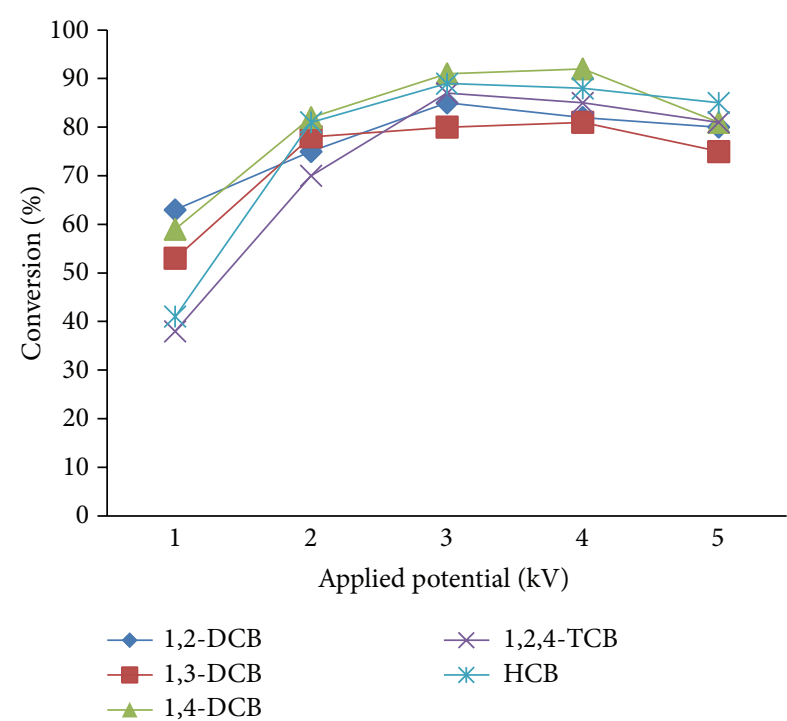

(b)

FIGURE 6: Effect of different applied potentials on the conversion ratio of chlorobenzenes (CBs) in the capillary microreactor at reaction time 20 min and $\mathrm{pH} 10$ by using (a) RHA-Pt and (b) RHA-Ti.

reaction times (10 $\mathrm{min}, 20 \mathrm{~min}$, and $30 \mathrm{~min}$ ) were applied. The reaction time was controlled manually; Figure 5 shows the conversion percentage of CBs with respect to these times. The dechlorination increases with the increase in reaction time up to $20 \mathrm{~min}$, by using RHA-Pt catalyst (Figure 5(a)), while the best time for the dechlorination of CBs by using RHA-Ti as catalyst was $10 \mathrm{~min}$ (Figure 5(b)).

3.2.2. Applied Potential. In order to achieve a high detoxification of COCs, different potentials were applied in the range of $1-5 \mathrm{kV}$ at a constant current of $200 \mu \mathrm{A}$. Figure 6 shows the influence of the applied potential on the HDC reactions. As can be seen, a maximum detoxification of COCs by both catalysts (RHA-Pt and RHA-Ti) was obtained by using $3 \mathrm{kV}$. In a glass capillary microreactor, high potential (in $\mathrm{kV}$ range) was applied to create in situ generation of hydrogen as well as to expedite the activation of catalysts for the detoxification of chlorobenzene. Moreover, the higher applied potential increases the analyte interaction with the catalyst particles and enhances the hydrodechlorination (HDC) reaction to detoxify chlorobenzene $[33,34]$.

3.2.3. Length of the Capillary Microreactor. We have reported in a previous study that for microdevices, using an electrophoretic separation at constant field, resolution is proportional to the square of the channel length [33]. Various lengths 
TABLE 2: Conversion ratio of CBs by the capillary-microreactor and the conventional method.

\begin{tabular}{|c|c|c|c|c|c|c|c|c|}
\hline \multirow{4}{*}{ Catalyst } & \multicolumn{8}{|c|}{ Method } \\
\hline & \multicolumn{3}{|c|}{ Glass capillary microreactor } & \multicolumn{4}{|c|}{ Conventional method } & \multirow[b]{3}{*}{$24 \mathrm{~h}$} \\
\hline & \multirow{2}{*}{$\begin{array}{l}\text { RHA-Ti } \\
10 \mathrm{~min}\end{array}$} & \multirow{2}{*}{$\begin{array}{l}\text { RHA-Pt } \\
20 \mathrm{~min}\end{array}$} & \multicolumn{3}{|c|}{ RHA-Pt } & \multicolumn{2}{|c|}{ RHA-Ti } & \\
\hline & & & $2 \mathrm{~h}$ & $16 \mathrm{~h}$ & $24 \mathrm{~h}$ & $2 \mathrm{~h}$ & $16 \mathrm{~h}$ & \\
\hline \multicolumn{9}{|c|}{ Compound name } \\
\hline $1,2-\mathrm{DCB}$ & 100 & 98 & 38 & 95 & 99 & 56 & 97 & 97 \\
\hline 1,3-DCB & 91 & 90 & 29 & 92 & 96 & 52 & 91 & 95 \\
\hline $1,4-\mathrm{DCB}$ & 93 & 97 & 35 & 93 & 97 & 50 & 95 & 100 \\
\hline $1,2,4-\mathrm{TCB}$ & 93 & 94 & 28 & 90 & 96 & 48 & 100 & 99 \\
\hline $\mathrm{HCB}$ & 89 & 94 & 25 & 87 & 92 & 42 & 88 & 95 \\
\hline
\end{tabular}

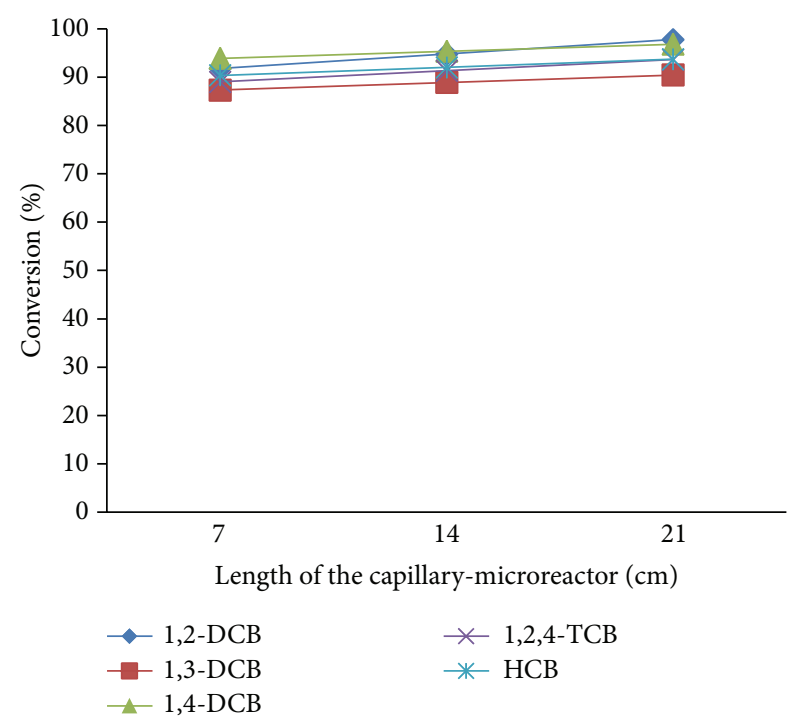

FIGURE 7: Effect of length of the capillary microreactor on the conversion ratio of CBs.

$(7 \mathrm{~cm}, 14 \mathrm{~cm}$, and $21 \mathrm{~cm})$ of the capillary were studied and significant improvement was obtained in the dechlorination of CBs when the length of the capillary was increased from $7 \mathrm{~cm}$ to $21 \mathrm{~cm}$ as shown in Figure 7.

3.2.4. Reaction $p H$. The $\mathrm{pH}$ of the solution is an important parameter which controls the rate of the dechlorination of CBs and CPs in the capillary microreactor. The $\mathrm{pH}$ values of the solution studied were 2.0, 7.0, and 10. The conversions of CBs and CPs by catalytic HDC in the capillary microreactor by different buffer solutions are used to neutralize the $\mathrm{HCl}$ which forms during the HDC reaction. Figure 8 shows the conversion of COCs involving different catalysts. The maximum conversion by using RHA-Pt catalyst was observed in the neutral range ( $\mathrm{pH} 7$ ) compared to other buffer solutions. This might be due to the dissolution of platinum particles [26]. However, when RHA-Ti was used as catalyst, the maximum conversion was obtained in alkaline range ( $\mathrm{pH} 10)$.
3.2.5. Quantitative Determination of Detoxification of COCs Using Microreactor with GC-MS Compared to Conventional Method. In order to evaluate the most favorable reaction conditions, the optimum dechlorination conditions were set as follows: reaction time of $20 \mathrm{~min}$, and $\mathrm{pH} 7$ when using RHA-Pt as the catalyst and $10 \mathrm{~min}$ applied potential of $3 \mathrm{kV}$ was used with a $21 \mathrm{~cm}$ long capillary microreactor, and $\mathrm{pH} 7$ when the catalyst was RHA-Ti. The results are summarized in Table 2. Compared with conventional detoxification method, the capillary microreactor provided high conversion ratios of CBs in shorter reaction time $(20 \mathrm{~min})$ with very little amount of the reactants.

In a glass capillary microreactor, high potential (in $\mathrm{kV}$ range) was applied to cause in situ generation of hydrogen as well as to expedite the activation of catalysts in the reaction for the detoxification of chlorobenzene. Moreover, the higher applied potential increases the analyte interaction with the nanoparticles and enhances the hydrodechlorination (HDC) reaction to detoxify chlorobenzene and chlorophenols. In our reactor, we believe that the electron density on the surface of the catalysts and the efficiency/performance of HDC reaction increase by the applied potential and thereby enhance conversion and dechlorination of CBs.

\section{Conclusions}

In this work, for the first time rice husk supported platinum (RHA-Pt) and titanium (RHA-Ti) catalysts were used to investigate the detoxification of chlorobenzenes in a glass capillary microreactor. RHA-Ti and RHA-Pt supported catalysts showed very interesting catalytic activity in the detoxification of chlorobenzenes in ambient conditions. The main advantage of capillary reactor is the in situ generation of hydrogen for the detoxification of chlorobenzenes. Only $20 \mathrm{~min}$ is sufficient when compared to $24 \mathrm{~h}$ reaction time in conventional method. The proposed method is simple, easy to use, and suitable for the detoxification of a wide range of chlorinated organic pollutants in environmental remediation applications. 


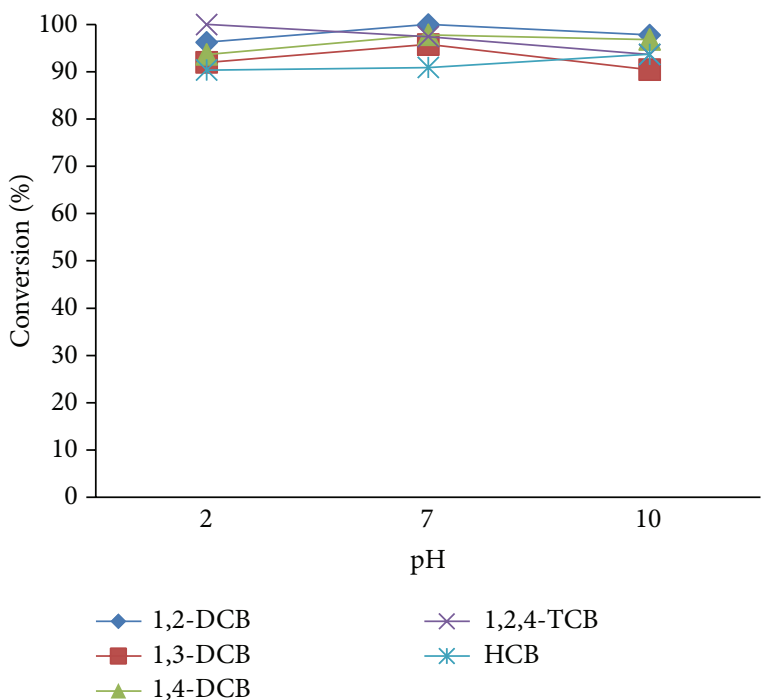

(a)

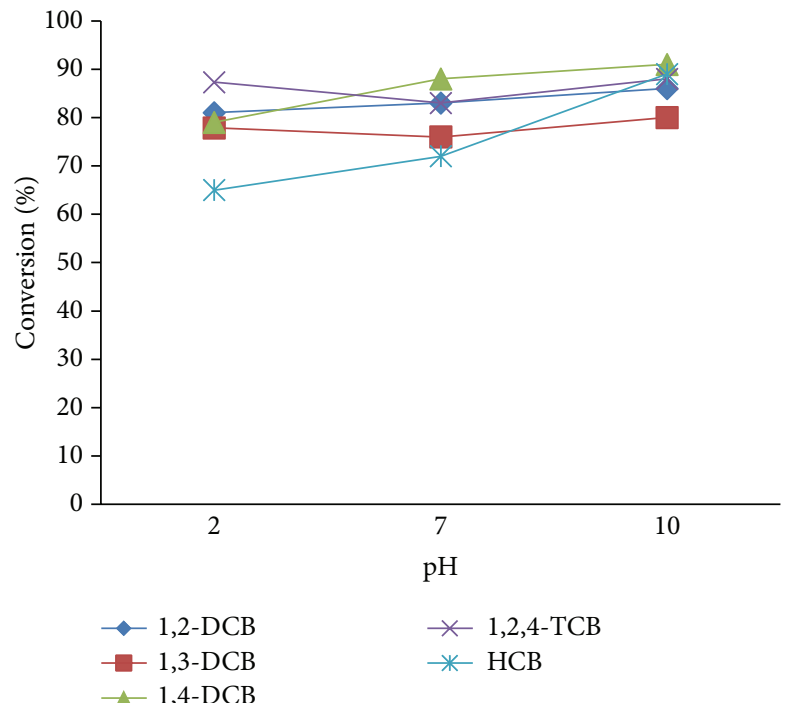

(b)

FIGURE 8: Effect of reaction $\mathrm{pH}$ on the conversion ratio of chlorobenzenes (CBs) in the capillary microreactor at 20 min and applied potential $(3 \mathrm{kV})$ by using (a) RHA-Pt and (b) RHA-Ti.

\section{Conflict of Interests}

The authors declare that there is no conflict of interests regarding the publication of this paper.

\section{Acknowledgment}

The authors gratefully acknowledge the support provided by the King Abdul Aziz City for Science and Technology through the Science and Technology Unit at King Fahd University of Petroleum and Minerals for funding Project no. 13-ENE277-04, as a part of the National Science Technology and Innovation Plan.

\section{References}

[1] V. Felis, P. Fouilloux, C. de Bellefon, and D. Schweich, “Threestep catalytic detoxification process of wastewater containing chlorinated aromatic compounds: experimental results and modeling issues," Industrial \& Engineering Chemistry Research, vol. 38, no. 11, pp. 4213-4219, 1999.

[2] I. M. Nangoi, P. K. Kiyohara, and L. M. Rossi, "Catalytic hydrodechlorination of chlorobenzene over supported palladium catalyst in buffered medium," Applied Catalysis B: Environmental, vol. 100, no. 1-2, pp. 42-46, 2010.

[3] C. Cui, X. Quan, S. Chen, and H. Zhao, "Adsorption and electrocatalytic dechlorination of pentachlorophenol on palladiumloaded activated carbon fibers," Separation and Purification Technology, vol. 47, no. 1-2, pp. 73-79, 2005.

[4] L. Calvo, M. A. Gilarranz, J. A. Casas, A. F. Mohedano, and J. J. Rodríguez, "Hydrodechlorination of 4-chlorophenol in water with formic acid using a Pd/activated carbon catalyst," Journal of Hazardous Materials, vol. 161, no. 2-3, pp. 842-847, 2009.

[5] S. Gryglewicz and W. Piechocki, "Hydrodechlorination of dichlorobenzenes and their derivatives over $\mathrm{Ni}-\mathrm{Mo} / \mathrm{C}$ catalyst: kinetic analysis and effect of molecular structure of reactant," Chemosphere, vol. 83, no. 3, pp. 334-339, 2011.

[6] W. F. Jardim, S. G. Moraes, and M. M. K. Takiyama, "Photocatalytic degradation of aromatic chlorinated compounds using $\mathrm{TiO}_{2}$ : toxicity of intermediates," Water Research, vol. 31, no. 7, pp. 1728-1732, 1997.

[7] F.-D. Kopinke, K. Mackenzie, R. Koehler, and A. Georgi, "Alternative sources of hydrogen for hydrodechlorination of chlorinated organic compounds in water on Pd catalysts," Applied Catalysis A: General, vol. 271, no. 1-2, pp. 119-128, 2004.

[8] US Environmental Protection Agency (US.EPA), National Pollutant Discharge Elimination System, Code of Federal Regulations, 40(122), US Government Printing Office, Washington, DC, USA, 1980-1988.

[9] W. J. Hayes and E. R. Laws, "Chlorinated hydrocarbon insecticides," in Handbook of Pesticide Toxicology, Classes of Pesticides, J. Hopkins, Ed., vol. 2, pp. 731-915, Academic Press, San Diego, Calif, USA, 1991.

[10] ATSDR ToxProfile, Toxicological Profile for Alpha-, Beta-, Gamma-, and Delta-Hexachlorocyclohexane, Agency for Toxic Substances and Disease Registry, US Department of Health and Human Services, Washington, DC, USA, 2005.

[11] S. Wang, B. Yang, T. Zhang, G. Yu, S. Deng, and J. Huang, "Catalytic hydrodechlorination of 4-Chlorophenol in an aqueous solution with $\mathrm{pd} / \mathrm{ni}$ catalyst and formic acid," Industrial and Engineering Chemistry Research, vol. 49, no. 10, pp. 4561-4565, 2010.

[12] E. R. Ritter, J. W. Bozzelli, and A. M. Dean, "Kinetic study on thermal decomposition of chlorobenzene diluted in hydrogen," Journal of Physical Chemistry, vol. 94, no. 6, pp. 2493-2504, 1990.

[13] M. Kosusko, M. E. Mullins, K. Ramanathan, and T. N. Rogers, "Catalytic oxidation of groundwater stripping emissions," Environmental Progress, vol. 7, no. 2, pp. 136-142, 1988.

[14] M. Wirtz, J. Klucik, and M. Rivera, "Ferredoxin-mediated electrocatalytic dehalogenation of haloalkanes by cytochrome 
P450 ${ }_{\text {cam }}$, Journal of the American Chemical Society, vol. 122, no. 6, pp. 1047-1056, 2000.

[15] C. Hu, B. Yue, and T. Yamase, "Photoassisted dehalogenation of organo-chlorine compounds by paratungstate A in aqueous solutions," Applied Catalysis A: General, vol. 194-195, pp. 99-107, 2000.

[16] J.-G. Lin and Y.-S. Ma, "Magnitude of effect of reaction parameters on 2-chlorophenol decomposition by ultrasonic process," Journal of Hazardous Materials, vol. 66, no. 3, pp. 291-305, 1999.

[17] W. W. Mohn and J. M. Tiedje, "Microbial reductive dehalogenation," Microbiological Reviews, vol. 56, no. 3, pp. 482-507, 1992.

[18] Y. Yamamoto and S. Tagawa, "Radiolytic and thermal dechlorination of organic chlorides adsorbed on molecular sieve 13X," Environmental Science and Technology, vol. 35, no. 10, pp. 21222127, 2001.

[19] B.-V. Chang, C.-W. Chiang, and S.-Y. Yuan, "Dechlorination of pentachlorophenol in anaerobic sewage sludge," Chemosphere, vol. 36, no. 3, pp. 537-545, 1998.

[20] C. M. Kao, C. T. Chai, J. K. Liu, T. Y. Yeh, K. F. Chen, and S. C. Chen, "Evaluation of natural and enhanced PCP biodegradaction at a former pesticide manufacturing plant," Water Research, vol. 38, no. 3, pp. 663-672, 2004.

[21] D.-S. Shen, X.-W. Liu, and H.-J. Feng, "Effect of easily degradable substrate on anaerobic degradation of pentachlorophenol in an upflow anaerobic sludge blanket (UASB) reactor," Journal of Hazardous Materials, vol. 119, no. 1-3, pp. 239-243, 2005.

[22] N. C. Concibido, T. Okuda, Y. Nakano, W. Nishijima, and M. Okada, "Enhancement of the catalytic hydrodechlorination of tetrachloroethylene in methanol at mild conditions by water addition," Tetrahedron Letters, vol. 46, no. 21, pp. 3613-3617, 2005.

[23] E. N. Balko, E. Przybylski, and F. V. Trentini, "Exhaustive liquid-phase catalytic hydrodehalogenation of chlorobenzenes," Applied Catalysis B, Environmental, vol. 2, no. 1, pp. 1-8, 1993.

[24] R. A. W. Johnstone, A. H. Wilby, and I. D. Entwistle, "Heterogeneous catalytic transfer hydrogenation and its relation to other methods for reduction of organic compounds," Chemical Reviews, vol. 85, no. 2, pp. 129-170, 1985.

[25] X. Liu, G. Lu, Y. Guo, Y. Wang, and X. Wang, "Catalytic transfer hydrogenolysis of 2-phenyl-2-propanol over palladium supported on activated carbon," Journal of Molecular Catalysis A: Chemical, vol. 252, no. 1-2, pp. 176-180, 2006.

[26] F. H. Ribeiro, C. A. Gerken, G. Rupprechter et al., "Structure insensitivity and effect of sulfur in the reaction of hydrodechlorination of 1,1-dichlorotetrafluoroethane $\left(\mathrm{CF}_{3}-\mathrm{CFCl}_{2}\right)$ over $\mathrm{Pd}$ catalysts," Journal of Catalysis, vol. 176, no. 2, pp. 352-357, 1998.

[27] C. D. Thompson, R. M. Rioux, N. Chen, and F. H. Ribeiro, "Turnover rate, reaction order, and elementary steps for the hydrodechlorination of chlorofluorocarbon compounds on palladium catalysts," The Journal of Physical Chemistry B, vol. 104, no. 14, pp. 3067-3077, 2000.

[28] F. J. Urbano and J. M. Marinas, "Hydrogenolysis of organohalogen compounds over palladium supported catalysts," Journal of Molecular Catalysis A: Chemical, vol. 173, no. 1-2, pp. 329-345, 2001.

[29] T. Naota, H. Takaya, and S.-L. Murahashi, "Rutheniumcatalyzed reactions for organic synthesis," Chemical Reviews, vol. 98, no. 7, pp. 2599-2660, 1998.

[30] Z. M. De Pedro, J. A. Casas, L. M. Gomez-Sainero, and J. J. Rodriguez, "Hydrodechlorination of dichloromethane with a Pd/AC catalyst: reaction pathway and kinetics," Applied Catalysis B: Environmental, vol. 98, no. 1-2, pp. 79-85, 2010.
[31] J. Bedia, L. M. Gómez-Sainero, J. M. Grau, M. Busto, M. MartinMartinez, and J. J. Rodriguez, "Hydrodechlorination of dichloromethane with mono- and bimetallic Pd-Pt on sulfated and tungstated zirconia catalysts," Journal of Catalysis, vol. 294, pp. 207-215, 2012.

[32] F. Adam, J. N. Appaturi, R. Thankappan, and M. A. M. Nawi, "Silica-tin nanotubes prepared from rice husk ash by solgel method: characterization and its photocatalytic activity," Applied Surface Science, vol. 257, no. 3, pp. 811-816, 2010.

[33] C. Basheer, F. S. J. Hussain, H. K. Lee, and S. Valiyaveettil, "Design of a capillary-microreactor for efficient Suzuki coupling reactions," Tetrahedron Letters, vol. 45, no. 39, pp. 7297 7300, 2004.

[34] C. Basheer, S. Swaminathan, H. K. Lee, and S. Valiyaveettil, "Development and application of a simple capillary-microreactor for oxidation of glucose with a porous gold catalyst," Chemical Communications, no. 3, pp. 409-410, 2005.

[35] F. Adam, J. N. Appaturi, Z. Khanam, R. Thankappan, and M. A. M. Nawi, "Utilization of tin and titanium incorporated rice husk silica nanocomposite as photocatalyst and adsorbent for the removal of methylene blue in aqueous medium," Applied Surface Science, vol. 264, pp. 718-726, 2013. 

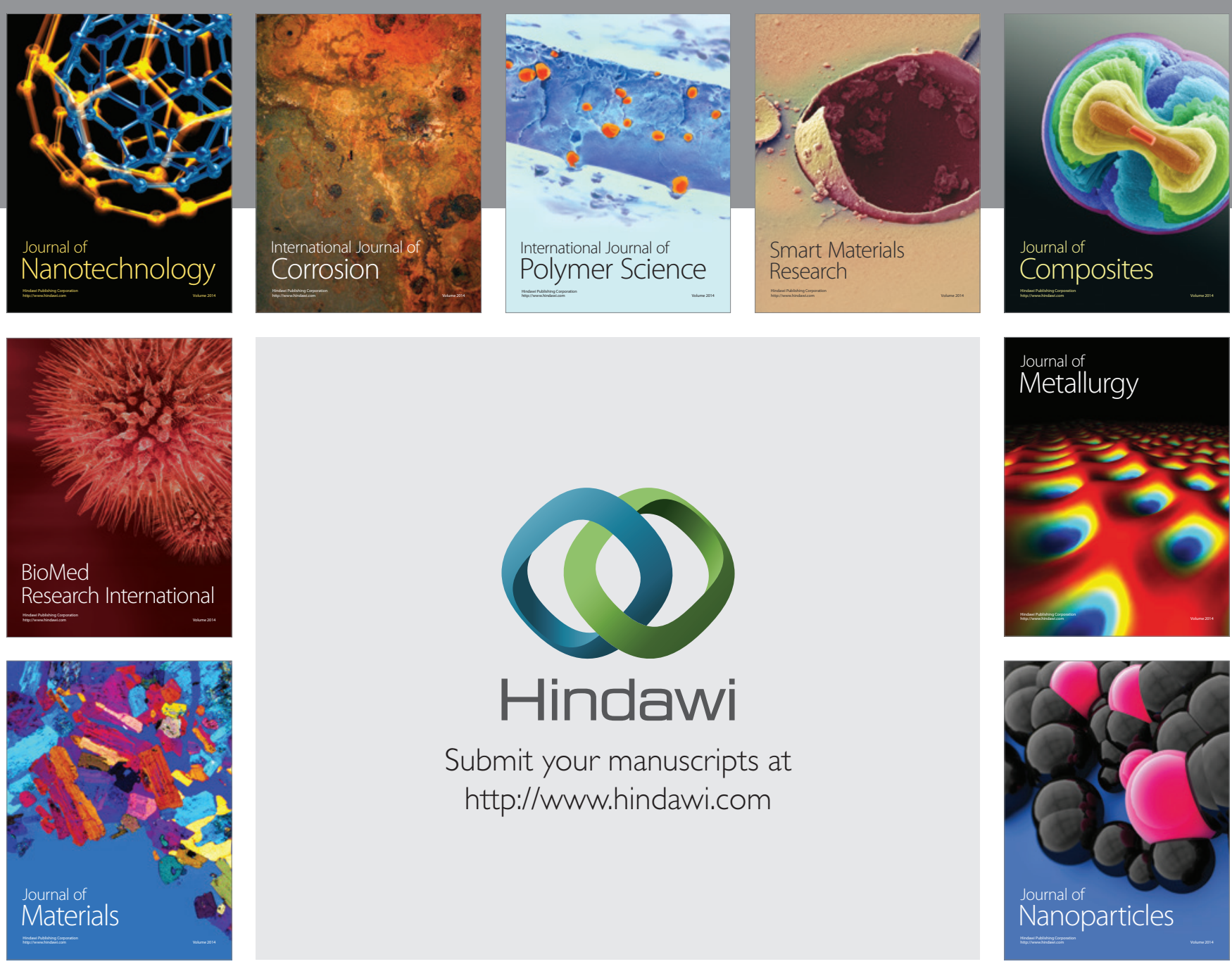

Submit your manuscripts at http://www.hindawi.com
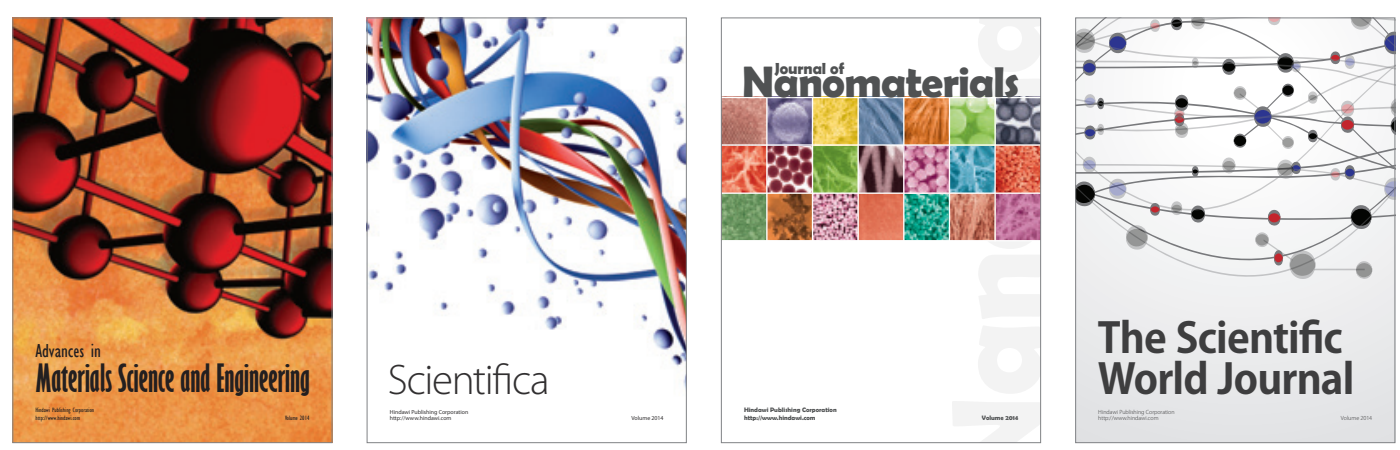

\section{The Scientific World Journal}
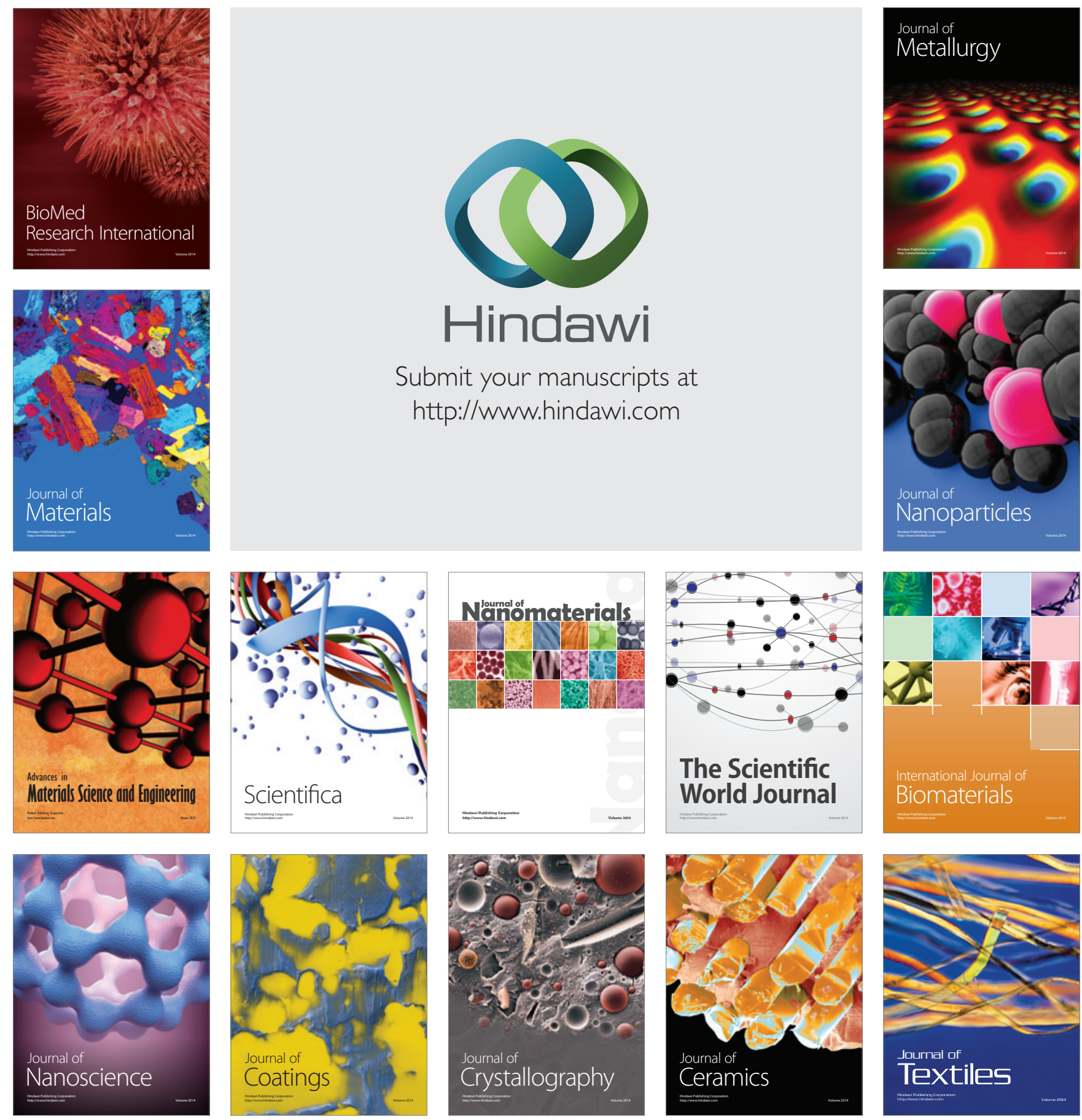